\title{
Klasifikasi Penentuan Kelayakan Pemberian Pinjaman pada Koperasi Karyawan Menggunakan Algoritma C4.5
}

\author{
Sunarti \\ Universitas Bina Sarana Informatika \\ e-mail: sunarti.sni@bsi.ac.id
}

Diterima: 05 Januari 2021; Direvisi: 26 Maret 2021; Disetujui: 04 April 2021

\begin{abstract}
Abstrak
Penelitian ini membahas klasifikasi dengan algoritma C4.5 penentuan kelayakan pemberian peminjaman pada koperasi karyawan Apartemen Senayan Jakarta. Permasalahan penentuan kelayakan pemberian pinjaman sangat menggangu perputaran keuangan koperasi. Metode Algoritma C4.5 dipergunakan dalam penetapan pengambilan keputusan penentuan kelayakan pemberian pinjaman, sehingga dapat diketahui level akurasi dan presisinya. Data dianalisis dengan memanfaatkan aplikasi Rapidminer. Rapidminer ialah sebuah software berbasiskan open source. Tujuan penelitian adalah untuk penentuan kelayakan pemberian pinjaman menggunakan Algoritma C.45 agar dapat memberikan solusi penentuan kelayakan pemberian pinjaman. Atribut yang digunakan terdiri dari status pernikahan, jenis kelamin, lokasi kerja, kedisiplinan, status pekerjaan, plafon pinjaman dan status tempat tinggal dengan keputusan layak dan tidak layak. Atribut yang paling berpengaruh terhadap penentuan kelayakan pemberian pinjaman adalah kedisiplinan. Dari hasil pengujian model yang terbentuk memiliki akurasi sebesar $85.19 \%$ dengan perolehan hasil pengolahan Receiver Operating Characteristic(ROC) mempergunakan data training sebesar 0.915 level diagnosa excellent classification. Model pohon keputusan yang ada dapat meningkatkan akurasi dalam penentuan kelayakan pemberian pinjaman untuk diajukan.
\end{abstract}

Kata kunci: Koperasi karyawan, Klasifikasi Pinjaman, Algoritma C4.5, Rapidminer

\begin{abstract}
This study discusses the classification with the C4.5 algorithm to determine the feasibility of providing loans to employee cooperatives at Senayan Jakarta Apartments. The problem of determining the feasibility of providing loans greatly interferes with the financial circulation of cooperatives. The C4.5 Algorithm method is used in determining the decision making to determine the feasibility of providing loans so that the level of accuracy and precision can be known. Data were analyzed using the Rapidminer application. Rapidminer is open-sourcebased software. The research objective is to determine the feasibility of granting loans using the C.45 Algorithm to provide solutions for determining the feasibility of providing loans. The attributes used consisted of marital status, gender, work location, discipline, employment status, loan ceiling, and residence status with appropriate and improper decisions. The attribute that most influences the determination of loan eligibility is discipline. From the test results, the model formed has an accuracy of $85.19 \%$ with the acquisition of Receiver Operating Characteristic(ROC) processing results using training data of 0.915 diagnostic levels of excellent classification. The existing decision tree model can improve the accuracy in determining the feasibility of a loan to be submitted.
\end{abstract}


Keywords: Employee cooperatives, Loan Classification, C4.5 Algorithm, Rapidminer

\section{PENDAHULUAN}

Koperasi adalah badan usaha beranggotakan orang perseorangan atau badan hukum koperasi. Kegiatan koperasi didasarkan pada prinsip-prinsip koperasi, dan gerakan sosial ekonomi berdasarkan kekerabatan [1]. Melalui gerakan koperasi, peningkatan kemampuan bekerjasama akan sangat menekan angka pengangguran [2]. Perihal perkoperasian diatur dengan Undang-Undang Nomor 25 Tahun 1992[3]. Adanya perubahan dari Undang-Undang Nomor 25 Tahun 1992 menjadi UU 17 tahun 2012 mengenai perkoperasian, mencakup reformasi hukum agar koperasi dapat terwujudkan untuk organisasi ekonomi yang sehat, kuat, mandiri dan tangguh beserta badan usaha yang andal dalam kegiatan didasarkan pada nilai dan prinsip koperasi [4]. Peran koperasi dapat membuktikan eksistensinya dalam menghadapi krisis sosial dan ekonomi saat ini. Ini merupakan bagian dapat mendorong bagi yang berminat jadi keanggotaan koperasi [1].

Penelitian ini dilakukan di koperasi karyawan simpan pinjam pada Apartemen Senayan Jakarta. Koperasi tersebut bergerak dalam bidang simpan pinjam yang beranggotakan karyawan pada apartemen tersebut [5]. Perkembangan bunga koperasi simpan pinjam berasal dari peminjam [6]. Koperasi ini sudah beroperasi hampir beberapa dekade, dan selalu ada kendala yang membuat karyawan sulit untuk meminjam uang dari koperasi tersebut. Kendalanya adalah memilih karyawan yang layak atau tidak layak meminjam pada koperasi [7]. Proses penentuan kelayakan dari peminjaman koperasi dikarenakan pengembalian pinjaman ada yang tidak tepat waktu [8]. Berdasarkan pada pencatatan peminjaman yang tidak tepat waktu pada saat ini memang lebih sedikit. Namun, analisis yang lebih mendalam terhadap data peminjam masih diperlukan untuk menentukan apakah peminjam layak atau tidak layak untuk diberikan pinjaman. Saat memutuskan peminjam mana yang akan dipinjamkan, keputusannya harus objektif.

Untuk memecahkan permasalahan dalam klasifikasi penentuan kelayakan pemberian pinjaman diperlukan metode data mining algoritma C4.5. Data mining dipergunakan mengekstrak dan mengidentifikasikan informasi. Proses pohon keputusan membuat sistem akan membantu dan mencarikan proses pengambilan keputusan dengan mempertimbangkan faktorfaktor yang terjadi[9]. Atribut yang digunakan yaitu status pernikahan, jenis kelamin, lokasi kerja, kedisiplinan, plafon pinjaman, status pekerjaan, dan status tempat tinggal. Untuk pengolahan data menggunakan perangkat lunak RapidMiner [10]. Alasan menggunakan algortima C4.5 adalah metode ini merupakan algoritma klasifikasi pohon keputusan. Pohon keputusan algoritma C4.5 dirancang menjadi tiga tahapan, diantaranya: memilih atribut sebagai root, pembuatan cabang untuk setiap nilai, dan membagi-bagi permasalahan dengan beberapa cabang [11], [8]. Fakta membuktikan bahwa algoritma C4.5 akurat dalam menentukan kredibilitas penerapan. Hasil penelitian dan evaluasi membuktikan bahwa metode tersebut memperoleh keakuratan data latih dan data uji [12]. Metode pohon keputusan yang diproses oleh aplikasi Rapidminer dapat mengidentifikasikan kelayakan peminjaman terbaik [11]. Dengan menggunakan data mining algoritma C4.5 untuk memprediksi jumlah pinjaman, fakta sangat besar dapat diklasifikasikan menjadi hasil dengan mengubahnya menjadi pohon keputusan yang menyajikan aturan [13]. Algoritma C4.5 mempunyai keahlian membuat keputusan dalam penetapan prediksi [14]

Tujuan penelitian yang dilakukan adalah untuk penentuan kelayakan pemberian pinjaman menggunakan Algoritma C.45 agar dapat memberikan solusi untuk penentuan kelayakan pemberian pinjaman pada koperasi karyawana Apartemen Senayan Jakarta. Melalui penjelasan permasalahannya, oleh sebab itu dibentuklah untuk sistem dapat mendukung mengklasifikasikan peminjaman koperasi karyawan simpan pinjam pada Apartemen Senayan Jakarta sebagai peminjaman yang layak atau tidak layak. Klasifikasi tersebut sungguh berguna menjaga pada proses bisnis koperasi simpan pinjam tersebut. Algoritma pohon keputusan 
Algoritma C4.5 dipilih sebab sangat mudah dipelajari saat terbaca hasil aturan yang terbentuk di pohon keputusan dengan proses pengolahan data menggunakan aplikasi Rapidminer.

\section{METODE PENELITIAN}

\subsection{Alur kerangka penelitian}

Proses penggambaran alur penelitian untuk meningkatkan pengetahuan mengenai penelitian ini. Setelah membuat kerangka penelitian, metode pohon keputusan Algortima C4.5 akan dipergunakan untuk menganalisis data yang ada. Skema penelitian yang dilaksanakan dapat dilihat gambar 1 sebagai berikut:

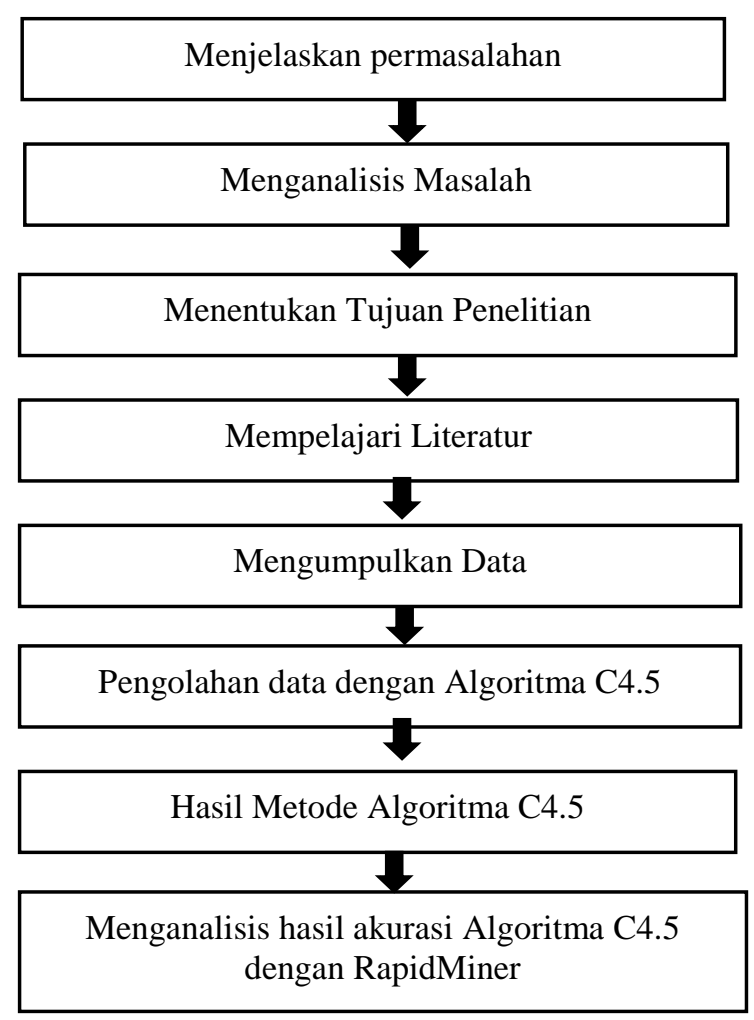

Gambar 1. Kerangka Penelitian

\subsection{Algoritma $\mathrm{C} 4.5$}

Algoritma C4.5 yaitu algoritma dipergunakan dalam menciptakan pohon putusan. Pohon putusan merupakan sebuah metode klasifikasi, bisa prediksikan secara kuat dan terkenal [15]. Tahapan dari algoritma C4.5 antara lain:

a. Tahap awal ialah penetapan akar dalam pohon keputusan. Pada pemilihan atribut untuk akar di algoritma C4.5, didasari oleh skor gain paling tinggi daripada atribut-atributnya pada dataset. Dalam penghitungan skor gain bisa dilihat dirumus 1 seperti dibawah ini:

$$
\operatorname{Gain}(\mathrm{S}, \mathrm{A})=\operatorname{Entropy}(\mathrm{S})-\sum_{i=1}^{n} \frac{\mid S i]}{|S|} i * \operatorname{Entropy}(S i)
$$

Penjelasannya: 
A : Atribute

S : Sampel

$\mathrm{n} \quad$ : Jumlah partisis pada himpunan atribut A

$|\mathrm{Si}|$ : Jumlah sampel di pertisi ke $-\mathrm{i}$

$|\mathrm{S}|$ : Jumlah sampel di S

b. Saat menghitung skor gain, tetapkan terlebih dahulu skor entropy pada setiap atribut yang ada. Gain mempunyai skor paling tinggi sehingga menjadi akar. Lakukan Langkah yang sama untuk mencari skor gain berikunya dengan mencari node selanjutnya. Penghitungan skor entropy pada rumus 2 seperti dibawah ini:

$$
\begin{aligned}
& \text { Entropy }(\mathrm{S})=\sum_{i=1}^{n}-p i \log 2 p i \\
& \text { Penjelasannya: } \\
& \mathrm{S} \quad \text { : Himpunan kasus } \\
& \mathrm{n} \quad \text { : Jumlah partisi S } \\
& \text { pi } \quad \text { Proporsi dari Si pada S }
\end{aligned}
$$

Saat membangun pohon keputusan, jumlah cabang dapat mencerminkan noise dalam data training. Pemangkasan pohon bisa dilaksanakan pada pengidentifikasian dan menghapus cabang-cabang tersebut. Pohon yang dipangkas akan berukuran lebih kecil dan lebih mudah dipahami. Pohon seperti itu umumnya lebih cepat dan lebih baik dalam klasifikasi[16].

\subsection{Rapid Miner}

Rapidminer merupakan sebuah aplikasi data mining dengan level akurasi dan metodologi yang tinggi, saat menggunakannya sangat mudah dan userfriendly. Aplikasi ini dapat digunakan sebagai aplikasi analisis data independen, atau sebagai mesin penambangan data yang diintegrasikan pada produknya. Banyaknya pemakai aplikasi Rapidminer lebih dari 40 negara/wilayah membagikan keunggulan kompetitif kepada penggunanya[17].

\section{HASIL DAN PEMBAHASAN}

Penelitian yang dilakukan menggunakan 304 data sample set anggota koperasi karyawan simpan pinjam pada Apartemen Senayan Jakarta. Atribut yang digunakan status pernikahan, jenis kelamin, lokasi kerja, kedisiplinan, plafon pinjaman, status pekerjaan, dan status tempat tinggal.

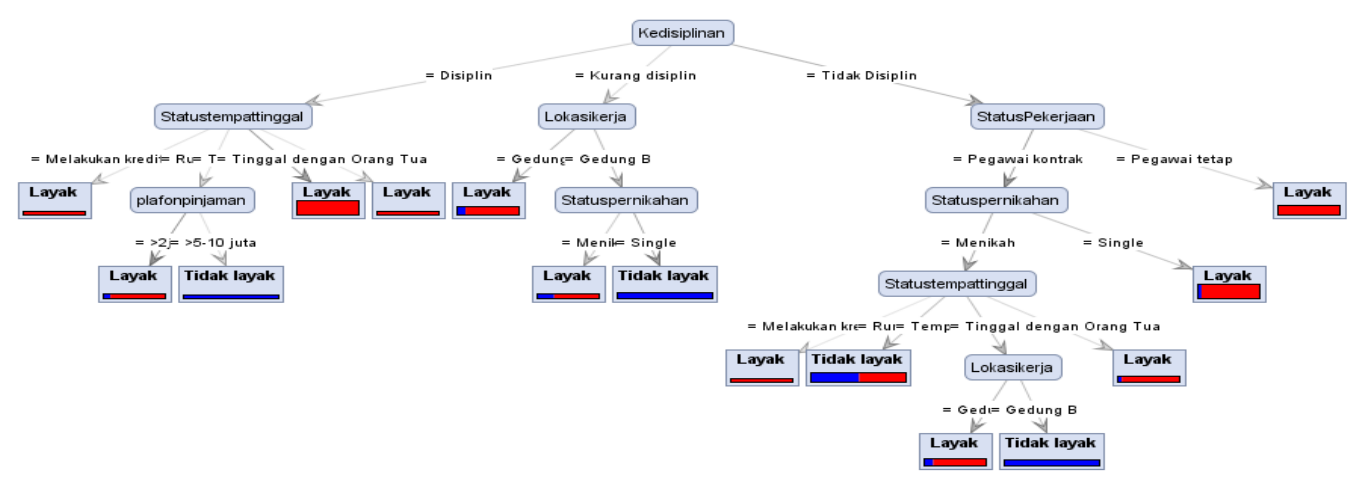

Gambar 2. Pohon keputusan klasifikasi penentuan kelayakan pemberian Pinjaman 
Berdasarakan data set, klasifikasi penentuan kelayakan ini dilakukan berdasarkan data klasifikasi anggota koperasi karyawan yang telah tersedia. Pohon keputusan algoritma C4.5 dibentuk melalui penentuan nilai gain dengan perolehan tertinggi dari setiap menghitung node, didasarkan node yang ditentukan, maka untuk klasifikasinya dapat dilihat pada gambar 2.

Perolehan hasil pengujian model sudah dilaksanakan menggunakan algoritma C4.5 dilaksanakan pengujian dengan level akurasi mempergunakan confussion matrix dan kurva ROC/AUC (Area Under Cover) menggunakan aplikasi Rapidminer dengan cara memasukkan data yang didapatkan dari koperasi karyawan simpan pinjam Apartemen Senayan Jakarta. Untuk perolehan hasil evaluasi sebagai berikut:

\subsection{Confusion Matrix}

Penghitungan akurasi menggunakan data training dengan algoritma C4.5. Dengan mengetahui data training sebanyak 304 record data, 30 data diklasifikasikan tidak layak dan 10 data diprediksikan layak, 35 data dinyatakan tidak layak dan 229 data dinyatakan layak. Class recall untuk kategori true layak adalah sebasar 95,82\% dan class recall untuk kategori true tidak layak sebesar $46,15 \%$.

Tabel 1. Model confusion matrix data training untuk algoritma C4.5.

\begin{tabular}{lccc}
\hline \multicolumn{4}{c}{ accuracy: $85.19 \%+/-4.97 \%$ (mikro: 85.20\%) } \\
\hline & true Tidak layak & true Layak & class precision \\
pred. Tidak layak & 30 & 10 & $75.00 \%$ \\
pred. Layak & 35 & 229 & $86.74 \%$ \\
class recall & $46.15 \%$ & $95.82 \%$ & \\
\hline
\end{tabular}

Perolehan hasil untuk confusion matrix ditabel 1, untuk langkah berikutnya dilaksanakan penghitungan untuk skor accuracy, precision, dan recall. Pembandingan skor accuracy, precision, dan recall yang sudah dilakukan penghitungan pada metode algoritma C4.5.

\subsection{Kurva $R O C$}

Data penghitungan bisa memvisualisasikan menggunakan kurva ROC (Receiver Operating Characteristic) atau AUC (Area Under Curve). Untuk ROC mempunyai level skor diagnosa antara lain:

a). Akurasi yang mempunyai nilai $0.90-1.00=$ excellent classification

b). Akurasi yang mempunyai nilai $0.80-0.90=$ good classification

c). Akurasi yang mempunyai nilai $0.70-0.80=$ fair classification

d). Akurasi yang mempunyai nilai $0.60-0.70=$ poor classification

e). Akurasi yang mempunyai nilai $0.50-0.60=$ failure

perolehan hasil pengolahan ROC pada algoritma C4.5 mempergunakan data training sebesar 0.915 (dapat dilihat pada gambar 3) perolehan level diagnosa excellent classification.

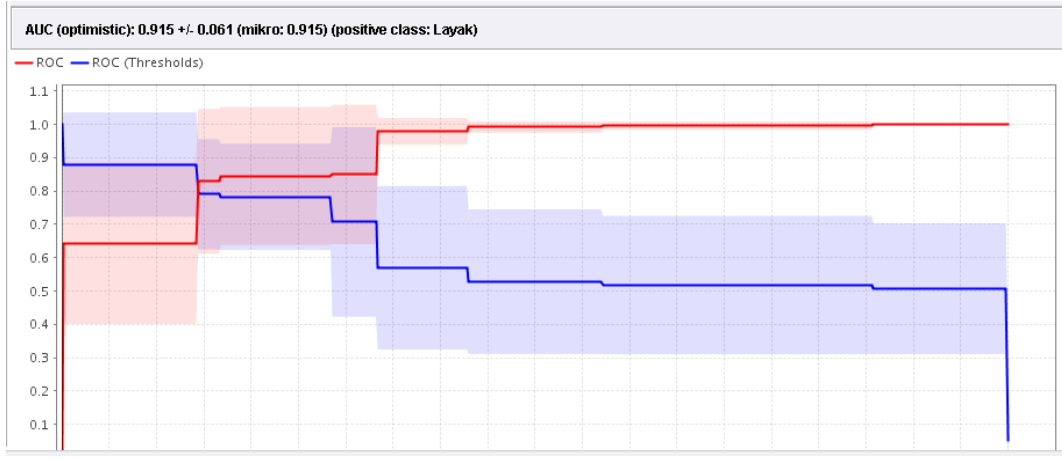

Gambar 3. Kurva ROC metode algortima C4.5 
Pada pohon keputusan gambar 2 model decision tree klasifikasi penentuan kelayakan pemberian pinjaman koperasi karyawan pada apartemen Senayan Jakarta maka dijabarkan seperti dibawah ini untuk rule yang terbentuk:

Kedisiplinan $=$ Disiplin

| Statustempattinggal $=$ Melakukan kredit dengan bank: Layak $\{$ Tidak layak $=0$, Layak $=5\}$

| Statustempattinggal $=$ Rumah sewa

| | plafonpinjaman $=>2$ juta: Layak $\{$ Tidak layak $=1$, Layak $=7\}$

| | plafonpinjaman $=>5-10$ juta: Tidak layak $\{$ Tidak layak $=1$, Layak $=0\}$

| Statustempattinggal $=$ Tempat tinggal sendiri $:$ Layak $\{$ Tidak layak $=0$, Layak=62 $\}$

| Statustempattinggal $=$ Tinggal dengan Orang Tua: Layak $\{$ Tidak layak=0, Layak=3 $\}$

Kedisiplinan $=$ Kurang disiplin

| Lokasikerja $=$ Gedung A: Layak $\{$ Tidak layak=4, Layak=23 $\}$

Lokasikerja $=$ Gedung $\mathrm{B}$

| | Statuspernikahan $=$ Menikah: Layak $\{$ Tidak layak=2, Layak=5 $\}$

| | Statuspernikahan $=$ Single: Tidak layak $\{$ Tidak layak $=16$, Layak $=0\}$

Kedisiplinan $=$ Tidak Disiplin

StatusPekerjaan $=$ Pegawai kontrak

| | Statuspernikahan = Menikah

| | | Statustempattinggal $=$ Melakukan kredit dengan bank: Layak $\{$ Tidak layak $=0$, Layak $=1\}$

| Statustempattinggal $=$ Rumah sewa: Tidak layak $\{$ Tidak layak=17, Layak=16 $\}$

| | Statustempattinggal $=$ Tempat tinggal sendiri

1 | | Lokasikerja = Gedung A: Layak $\{$ Tidak layak=3, Layak=16 $\}$

1 | Lokasikerja = Gedung B: Tidak layak $\{$ Tidak layak=16, Layak=0 $\}$

1 | Statustempattinggal $=$ Tinggal dengan Orang Tua: Layak $\{$ Tidak layak=1, Layak=12 $\}$

| Statuspernikahan = Single: Layak $\{$ Tidak layak $=4$, Layak $=52\}$

StatusPekerjaan $=$ Pegawai tetap: Layak $\{$ Tidak layak $=0$, Layak $=37\}$

Bentuk dari algoritmanya jika diinputkan pada program aplikasi, untuk perolehan hasilnya seperti dibawah ini:

IF Kedisiplinan=Disiplin AND Statustempattinggal=melakukan kredit dengan bank THEN layak

IF Kedisiplinan=Disiplin AND Statustempattinggal=Rumah sewa AND plafonpinjaman= $>$ 2juta THEN Layak

IF Kedisiplinan=Disiplin AND Statustempattinggal= Rumah sewa AND plafonpinjaman=>5-10 juta THEN Tidak layak

IF Kedisiplinan=Disiplin AND Statustempattinggal=Tempat tinggal sendiri THEN Tidak Layak

IF Kedisiplinan=Disiplin AND Statustempattinggal=Tinggal dengan Orang Tua THEN Layak

IF Kedisiplinan=Kurang disiplin AND Lokasikerja=Gedung A THEN Layak

IF Kedisiplinan=Kurang disiplin AND Lokasikerja=Gedung B AND Statuspernikahan= Menikah THEN Layak

IF Kedisiplinan=Kurang disiplin AND Statuspernikahan= Single THEN Tidak layak

IF Kedisiplinan=Tidak Disiplin AND StatusPekerjaan=Pegawai kontrak AND Statuspernikahan=Menikah AND Statustempattinggal=Melakukan kredit dengan bank THEN Layak

IF Kedisiplinan=Tidak Disiplin AND Statustempattingga=Rumah sewa THEN Tidak layak

IF Kedisiplinan=Tidak Disiplin AND Statustempattinggal=Tempat tinggal sendiri AND Lokasikerja $=$ Gedung A THEN Layak

IF Kedisiplinan=Tidak Disiplin AND Statustempattinggal=Tempat tinggal sendiri AND Lokasikerja=Gedung B THEN Tidak layak

IF Kedisiplinan=Tidak Disiplin AND Statustempattinggal=Tinggal dengan Orang Tua THEN Layak

IF Kedisiplinan=Tidak Disiplin AND Statustempattinggal=Tinggal dengan Orang Tua AND Statuspernikahan=Single THEN Layak 
IF Kedisiplinan=Tidak Disiplin AND Statustempattinggal=Tinggal dengan Orang Tua AND StatusPekerjaan=Pegawai tetap THEN Layak

Penelitian yang dilakukan mempergunakan decision tree algoritma C4.5 dengan penerapannya memanfaatkan aplikasi RapidMiner bisa menaikkan akurasi analisis pemberian pinjaman pada koperasi karyawan Apartemen Senayan Jakarta. Hasil penelitian yang sudah dilakukan diperolehnya akurasi data excellent classification dengan nilai yang didapatkan 0.915 dari hasil pengolahan Receiver Operating Characteristic (ROC) pada algoritma C4.5. Manfaat dari penggunaan algoritma $\mathrm{C} 4.5$ untuk klasifikasi ialah dapat menentukan pola penentuan kelayakan peminjaman pada koperasi karyawan dengan memaksimalkan penggunaan data di Apartemen Senayan Jakarta, membantu pengambilan keputusan dan menetapkan rencana dalam penentuan kelayakan peminjaman pada koperasi karyawan di Apartemen Senayan Jakarta. Sedangkan kelemahan dari penggunaan algoritma C4.5 untuk klasifikasi ialah belum mampu mengontrol kevalidan dari data, hanya mempergunakan teknik pohon keputusan, tidak melakukan perbandingan dengan algoritma lain pada data mining, maka mengakibatkan pola klasifikasi akan mejadi lebih sedikit.

\section{KESIMPULAN}

Penelitian sudah dilaksanakan, maka kesimpulannya decision tree valid untuk klasifikasi penentuan kelayakan pemberian pinjaman. Level akurasinya mencapai $85.19 \%$. Hasil dari akurasi data dapat diklasifikasikan excellent classification dengan nilai yang didapatkan 0.915 dari hasil pengolahan ROC pada algoritma C4.5 sehingga rule menghasilkan data dapat diterapkan dan dipergunakan untuk dijadikan panduan penentuan kelayakan pemberian pinjaman pada koperasi karyawan pada Apartemen Senayan Jakarta.

\section{SARAN}

Pengembangan penelitian berikutnya dapat dilanjutkan dengan memperbanyak atribut yang ada keterkaitan mengenai permasalahan kelayakan peminjaman koperasi karyawan. Dengan banyaknya atribut supaya level pemberian keputusan menjadi lebih baik. Bisa melakukan komparasi metode data mining yang lain, sehingga memperoleh pembanding yang lebih baik.

\section{DAFTAR PUSTAKA}

[1] P. H. Kurnia, "Model Klasifikasi Kelayakan Kredit Koperasi Karyawan Dengan Algoritma Decision Tree," Pros. SNATIF ke-6 Tahun 2019, no. 2007, pp. 96-101, 2019.

[2] Sudaryat, "Undang-Undang No.25 Tahun 1992 Tentang Perkoperasian dan Daya Dukungnya Terhadap Pemberdayaan Koperasi Syariah di Indonesia," Selisik, 2018. .

[3] F. Naeshela, "Peranan Koperasi Simpan Pinjam Credit Union $(\mathrm{Cu})$ Femung Pebaya Cabang Mentarang Di Kecamatan Mentarang Kabupaten Malinau," eJournal Pemerintah. Integr., vol. 4, no. 2, pp. 155-165, 2016.

[4] A. Fauzi, "UU 17 Tahun 2012 Tentang Perkoperasian," www.jogloabang.com, 2019.

[5] I. Riswanto et al., "Karyawan Menggunakan Metode Naïve Bayes," J. Infotronik, vol. 5, no. 1, pp. 11-16, 2020, doi: 10.32897/infotronik.2020.5.1.2.

[6] J. S. Parapat and A. S. Sinaga, "Data Mining Algoritma C4 . 5 Pada Klasifikasi Kredit Koperasi Simpan Pinjam,” J. Ilmu Tek. Elektro Komput. dan Inform., vol. 4, no. 2, pp. 144-154, 2018.

[7] K. S. Lubis, "Prosedur Pemberian Kredit Pada Koperasi Karyawan Simpan Pinjam 
Tanjung Jaya Pt . Ivo Mas Tunggal," J. Ilm. Ekon. dan Bisnis, vol. 14, no. 1, pp. 45-51, 2017.

[8] L. Farokhah and R. D. Indahsari, "Implementasi Decision Tree C4.5 Dalam Penentuan Pinjaman Uang Di Koperasi XYZ Di Banjarmasin," Klik - Kumpul. J. Ilmu Komput., vol. 6, no. 3, p. 293, 2019, doi: 10.20527/klik.v6i3.268.

[9] J. S. Parapat and A. S. Sinaga, "Data Mining Klasifikasi Data Nasabah Kredit KSU Taman Mandiri Data Mining Algoritma C4 . 5 Pada Klasifikasi Kredit Koperasi Simpan Pinjam," J. Ilmu Tek. Elektro Komput. dan Inform., vol. 4, no. Desember 2018, 2018, doi: 10.26555/jiteki.v4i2.11416.

[10] S. Wahyuni, K. S. S, and Mochammad Iswan Perangin-Angin, "Implementasi Rapidminer Dalam Menganalisa Data Mahasiswa Drop Out," vol. 10, pp. 2013-2016, 2017.

[11] S. A. Lusinia, "Algoritma C4.5 Dalam Menganalisa Kelayakan Kredit(Studi Kasus Di Koperasi Pegawai Republik Indonesia (KP RI) Lengayang Pesisir Selatan, Painan Sumatera Barat)," J. KomTekInfo, vol. 1, no. 2, pp. 6-10, 2014, [Online]. Available: http://lppm.upiyptk.ac.id/KomTekInfo/index.php/KOMTEKINFO/article/download/8/8.

[12] T. B. Santoso and D. Sekardiana, "Penerapan Algoritma C4.5 untuk Penentuan Kelayakan Pemberian Kredit," J. Algoritm. Log. dan Komputasi, vol. II, no. 1, pp. 130137, 2019.

[13] S. D. Manullang, E. Buulolo, and I. Lubis, "Implementasi Data Mining Dalam Memprediksi Jumlah Pinjaman Dengan Algoritma C4 . 5 Pada Kopdit CU Damai Sejahtera," J. Sist. Komput. dan Inform., vol. 1, pp. 265-272, 2020, doi: 10.30865/json.v1i3.2153.

[14] S. Sunarti, "Prediksi Promosi Jabatan Karyawan Dengan Algoritma C4.5 (Studi Kasus: Apartemen Senayan Jakarta)," Techno.Com, vol. 18, no. 4. Universitas Dian Nuswantoro, pp. 288-298, 2019, doi: 10.33633/tc.v18i4.2471.

[15] F. A. Hermawati, Data Mining. Yogyakarta: CV Andi Offset, 2013.

[16] H. Wiyana, S. Kurniawan, and T. S.Ali, "Memprediksi Transaksi Nasabah Pada Koperasi Simpan Pinjam Pt. Asuransi Staco Mandiri Dengan Algoritma C4.5," Semin. Nas. Teknol. Inf. dan Komun. 2018 (SENTIKA 2018), vol. 2018, no. Sentika, pp. 23-24, 2018.

[17] L. A. dan Dennis, Aprilia, Donny Aji Baskoro and I. W. S. Wicaksana, Belajar Data Mining dengan Rapid Miner. Jakarta: Gramedia Pustaka Utama, 2013. 